\title{
ESPAÇO GEOGRÁFICO, PRODUÇÃO E MOVIMENTO: UMA REFLEXÃO SOBRE O CONCEITO DE CIRCUITO ESPACIAL PRODUTIVO
}

\section{Geographical Space, production and movement: A reflection about the concept of productive spatial circuit}

Ricardo Castillo

Geógrafo, Professor Dr. do Departamento de Geografia do Instituto de Geociências da Universidade Estadual de Campinas (UNICAMP)

Pesquisador CNPq

Campinas/SP - Brasil castillo@ige.unicamp.br

Samuel Frederico

Geógrafo, Professor Dr. do Departamento de Geografia do Instituto de Geociências e Ciências Exatas da Universidade Estadual Paulista (UNESP-Rio Claro)

Rio Claro/SP - Brasil sfrederico@rc.unesp.br

Artigo recebido para publicação em 16/12/2010 e aceito para publicação em 27/12/2010

RESUMO: $\quad O$ propósito deste artigo é demonstrar a importância e a operacionalidade dos conceitos de circuito espacial produtivo e círculos de cooperação no espaço, num momento histórico em que as esferas da produção e da troca tornam-se geograficamente mais dispersas, fazendo da circulação uma prioridade e um campo de atuação estratégica de Estados e empresas. Procura-se alcançar esse objetivo em três passos: 1) elaboração de uma discussão teórica com base nos autores que propuseram e procuraram desenvolver os conceitos; 2) proposição de uma distinção entre circuito espacial produtivo e cadeia produtiva; 3) uma breve análise da produção agrícola moderna em áreas de fronteira agrícola no território brasileiro à luz dessa teoria.

Palavras-chave: Circuito espacial produtivo. Circulação. Fronteira agrícola. Território brasileiro.

ABSTRACT: The aim of this article is to demonstrate the importance and the operational feasibility of the concepts of the productive spatial circuit and cooperation circles in space, in an historical moment when the spheres of production and exchange become more scattered geographically, making circulation a priority and a strategic acting field of Estates and companies. It seeks to achieve this objective through three steps: 1) elaboration of a theoretical debate based on authors that proposed and sought to develop those concepts; 2) proposition of a distinction between productive spatial circuit and productive chain; 3) a brief analysis of modern agricultural production in agricultural expansion areas in the Brazilian territory in the light of this theory.

Keywords: Productive spatial circuit. Circulation. Agricultural expansion. Brazilian territory. 


\section{INTRODUÇÃO}

Uma das características mais marcantes do atual período histórico encontra-se no exponencial aumento dos fluxos materiais e imateriais, decorrente da gradativa mundialização da produção, da prestação de serviços e do consumo, pelo menos para alguns setores e circuitos econômicos.

Mas a assim chamada globalização, emergente na década de 1970, não seria possível sem uma base geográfica, constituída por uma esfera material e uma esfera normativa na escala mundial. A expansão e a modernização do sistema de telecomunicações e de transportes formam a essência dessa base material. A base normativa, por sua vez, configura-se no conjunto de regras estabelecidas para regular, técnica e politicamente, os mercados internacionalizados, através de padronizações produtivas, certificações de qualidade de produtos e serviços, conversão de alguns bens em commodities, importância crescente de câmaras de arbitragem internacionais, papel mais contundente de instituições multilaterais como a Organização Mundial do Comércio, entre outros aspectos.

Nesse novo contexto, caracterizado pelo aprofundamento da divisão territorial do trabalho e expresso na especialização regional produtiva e na racionalidade que preside o movimento das mercadorias, os conceitos de circuito espacial da produção e de círculos de cooperação no espaço (SANTOS, 1986; SANTOS; SILVEIRA, 2001) tornam-se fundamentais para o entendimento da organização, da regulação e do uso dos territórios.

A expansão dos circuitos espaciais produtivos torna mais complexa a gestão e o ordenamento dos fluxos materiais e imateriais, fazendo das grandes corporações os agentes privilegiados da articulação entre os lugares, ou seja, da unificação das diversas etapas, geograficamente segmentadas, da produção. A logística, compreendida como a manifestação hegemônica da circulação no período histórico atual, torna-se prioridade de agentes públicos e estratégia de grandes empresas para conferir fluidez e racionalidade aos circuitos espaciais produtivos, passando a ser uma das mais contundentes expressões geográficas da globalização, imprescindível para a realização da produção em escala mundial.
Diante disso, o propósito desse pequeno ensaio é demonstrar a importância e a operacionalidade dos conceitos de circuito espacial produtivo e círculos de cooperação no espaço, num momento histórico em que as esferas da produção e da troca tornam-se geograficamente mais dispersas, fazendo da circulação uma prioridade e um campo de atuação estratégica de Estados e empresas.

Diante da magnitude desse objetivo e dos inúmeros caminhos teóricos que se oferecem para tratar do assunto, optamos por dividir nossa abordagem em três partes. Na primeira, procuramos resgatar as origens e reconstituir algumas discussões fundamentais sobre a idéia de circuitos espaciais, através de um diálogo com alguns autores que consideramos protagonistas desse debate. Em seguida, propomos estabelecer uma distinção entre os conceitos de circuito espacial produtivo e cadeia produtiva, identificando seus objetivos e possibilidades analíticas particulares. A confusão entre um conceito e outro tem inibido um desenvolvimento mais pleno da abordagem geográfica da unidade entre produção, circulação, troca e consumo. Por fim e com base em nossa própria experiência de pesquisa, levantamos alguns aspectos dos circuitos espaciais de produtos agrícolas em áreas de fronteira no território brasileiro.

\section{CIRCUITO ESPACIAL PRODUTIVO E CÍRCU- LOS DE COOPERAÇÃO NO ESPAÇO: UMA DISCUSSÃO CONCEITUAL}

A Geografia, assim como a Economia Espacial e a Ciência Regional, tem na localização das atividades econômicas e na articulação entre os diferentes lugares dois de seus temas principais.

Com a crescente especialização produtiva dos lugares, possibilitada pela combinação entre o desenvolvimento dos sistemas de transportes e comunicações e a política de Estados e empresas, aumentam os fluxos materiais e informacionais, distanciando cada vez mais os locais de produção dos locais de consumo, tornando mais complexas a distribuição espacial das atividades econômicas e a articulação entre as diferentes etapas, em diferentes lugares, da produção.

Dessa forma, os conceitos de circuito espacial da produção e círculos de cooperação no espaço 
tornam-se imprescindíveis para a melhor compreensão dessa articulação e suas implicações sócio-espaciais. Para Moraes (1985, p.155), esses termos encerram conceitos essenciais para "compreender a divisão social do trabalho numa perspectiva multiescalar".

A noção de circuito espacial produtivo enfatiza, a um só tempo, a centralidade da circulação (circuito) no encadeamento das diversas etapas da produção; a condição do espaço (espacial) como variável ativa na reprodução social; e o enfoque centrado no ramo, ou seja, na atividade produtiva dominante (produtivo).

A origem da idéia de circuito de produção, segundo Moraes (id.), remonta a Marx (2008), quando esse autor enfatiza a unidade contraditória entre a produção, a distribuição, a troca e o consumo. A produção não se limitaria ao ato produtivo em si, mas seria definida pela circulação da mercadoria, desde a sua produção até o consumo final, momento em que se realiza a apropriação do excedente (mais-valia). Dessa maneira, o circuito produtivo pode ser entendido como uma unidade, com elementos distintos em seu interior. A circulação ganha destaque, demonstrando o caráter essencial dos fluxos para a realização da produção.

Além de situar o devido papel da circulação, a noção de circuito espacial produtivo atribui um destaque igualmente importante à categoria espaço. Moraes (1985, p.156) enfatiza que "discutir os circuitos espaciais da produção é discutir a espacialidade da produção-distribuição-troca-consumo como movimento circular constante". Para nós, embasados em Santos (1977, 1997; 1978), o espaço é entendido como uma instância social, ou seja, um conjunto de fatores e funções condiciona e transforma a reprodução social. As formas geográficas apresentam-se de maneira mais ou menos funcional à difusão do capital. Sua singularidade encontra-se em sua base material, distinguindo-a das formas econômicas, jurídicas, culturais e políticas. A presença de formas com conteúdos funcionais aos interesses das grandes corporações possibilita a instalação, num mesmo subespaço, de diversos circuitos espaciais produtivos, tornando o espaço um mosaico, no qual convivem formas com racionalidades e conteúdos diversos, concebidas e implantadas em momentos distintos. É assim que o espaço geográfico pode ser compreendido como uma acumulação desigual de tempos (SANTOS, 1996), re- velando a coexistência entre diferentes temporalidades num mesmo lugar, região ou território.

O termo "produtivo", por sua vez, advém da análise centrada no "ramo", envolvendo uma gama variada de agentes, sobretudo as firmas. O enfoque no produto diferencia a noção de circuito espacial produtivo da idéia dos dois circuitos da economia urbana, proposta por Santos $(1979 ; 2004)$. Nestes, o centro da análise volta-se para o agente econômico, independentemente do ramo (ARROYO, 2008), envolvendo diversos produtos. Os conceitos de circuito espacial da produção e de circuitos da economia urbana podem ser trabalhados de maneira complementar, uma vez que tanto o circuito inferior quanto o superior fazem parte de circuitos espaciais produtivos de tamanho e características técnicas e organizacionais distintas.

O emprego da noção de circuito espacial da produção na Geografia e demais disciplinas vinculadas à temática espacial é relativamente recente. Segundo Moraes (1985), a formulação mais direta desta problemática aparece no projeto "MORVEN: Metodologia para o Diagnóstico Regional", desenvolvido pelo Centro de Estudios del Desarrollo (CENDES) da Universidade Central da Venezuela no final da década de 1970. Para Santos (1986), o Projeto tinha como objetivo estudar a segmentação dos espaços nacionais e a ação dos diferentes agentes produtivos sobre o espaço nos países do Terceiro Mundo. Sonia Barrios (1976), uma das autoras do projeto, observa que os "circuitos de produção e acumulação se estruturam a partir de uma atividade produtiva definida como primária ou inicial" e possuem "uma série de fases ou escalões correspondentes aos distintos processos de transformação por que passa o produto principal da atividade até chegar ao consumo final" (BARRIOS, 1976 apud SANTOS, 1986, p.121).

No mesmo projeto, Milton Santos propõe a existência de três circuitos: "circuito por ramos", "circuito de firmas" e "circuito espacial ou territorial". $\mathrm{O}$ primeiro refere-se às relações técnicas e sociais, à localização das atividades e à tipologia dos lugares. O segundo trata da ação das grandes empresas, suas relações econômicas e círculos de cooperação estabelecidos em diferentes escalas. Por fim, a noção de circuito espacial sintetiza os precedentes, indicando ao mesmo tempo o uso do território por ramos produtivos 
e pelas firmas. Ele nos oferece, a cada momento, a situação de cada fração do espaço em função da divisão territorial do trabalho de um país. Santos (1986) enfatiza o papel ativo do espaço geográfico ao ressaltar que a análise dos circuitos espaciais deve relacionar a internacionalização do capital às heranças espaciais de cada país, articulando as relações de produção do passado às atuais.

Ao ressaltar a necessidade de renovação, no atual período, de diversas categorias e conceitos da Geografia, e dando continuidade ao debate anterior, Santos (1988) aponta a dificuldade de se falar em circuitos regionais de produção. $\mathrm{O}$ imperativo de uma mesma lógica global sobre diferentes lugares, os intensos intercâmbios entre localidades distantes, muitas vezes mais numerosos do que as relações estabelecidas com os lugares vizinhos, e a consequente especialização produtiva regional, tornariam inócua a compreensão de circuitos circunscritos regionalmente e fariam premente a sua substituição pelo conceito de circuitos espaciais de produção. Este abarca as diferentes etapas do processo produtivo, articulando dialeticamente o lugar e o mundo.

Para Arroyo (2008), os circuitos espaciais produtivos são formados por empresas de diversos tamanhos e que atingem de forma articulada diferentes frações do território. "Essa articulação se expressa pelo movimento de inúmeros fluxos de produtos, idéias, ordens, informação, dinheiro, excedente. Enfim, pela circulação" (id., p. 30). É a intrínseca relação entre o conceito de circuito espacial produtivo e a idéia de movimento que, segundo Santos e Silveira (2001), torna o emprego do termo extremamente importante na análise geográfica. Nas palavras dos autores:

\section{A divisão territorial do trabalho pode nos dar apenas uma visão mais ou menos estática do espaço de um país. (...) Mas para entendermos o funcionamento do território é preciso captar o movimento, dai a proposta de abordagem que leva em conta os circuitos espaciais da produção. Estes são definidos pela circulação de bens e produtos e, por isso, oferecem uma visão dinâmica, apontando a maneira como os fluxos perpassam o território (SANTOS; SILVEIRA, 2001, p.143).}

$\mathrm{O}$ aumento das trocas materiais, possibilitado pelo aprofundamento da divisão territorial do trabalho, é o fato que torna operacional o conceito de circuito espacial produtivo. Segundo Arroyo (2001, p.57), este permite "agregar a topologia de diversas empresas em um mesmo movimento; mas, ao mesmo tempo, permite captar uma rede de relações que se dão ao longo do processo produtivo, atingindo uma topografia que abrange uma multiplicidade de lugares e atores". Se, por um lado, as diversas etapas do processo capitalista se tornaram cada vez mais dispersas no espaço, por outro, estão cada vez mais articuladas pelas políticas das empresas, sobretudo as grandes, através da modernização e da expansão das redes técnicas de informação, portadoras de ordens, mensagens, capitais.

Isso evidencia a centralidade dos fluxos imateriais na análise geográfica. Daí a importância dos círculos de cooperação no espaço (SANTOS; SILVEIRA, 2001), entendidos como a relação estabelecida entre lugares e agentes por intermédio dos fluxos de informação. Os círculos de cooperação são essenciais por permitirem colocar em conexão as diversas etapas, espacialmente separadas, da produção, articulando os diversos agentes e lugares que compõem o circuito espacial da produção.

As noções de circuito espacial da produção e de círculos de cooperação no espaço permitem verificar a interdependência dos espaços produtivos, captando a unidade e a circularidade do movimento. Essas noções tornam mais nítidas as contradições espaciais expostas por Santos (1985) e exemplificadas pela dialética entre os arranjos espaciais pretéritos e as novas ações e objetos; a organização interna confrontada com os eventos externos; e a regulação híbrida (ANTAS JR., 2005) que envolve as ações do Estado e das empresas.

Com base nas discussões encaminhadas até aqui, podemos dizer que os circuitos espaciais de produção pressupõem a circulação de matéria (fluxos materiais) no encadeamento das instâncias geograficamente separadas da produção, distribuição, troca e consumo, de um determinado produto, num movimento permanente; os círculos de cooperação no espaço, por sua vez, tratam da comunicação, consubstanciada na transferência de capitais, ordens, informação (fluxos imateriais), garantindo os níveis de organização 
necessários para articular lugares e agentes dispersos geograficamente, isto é, unificando, através de comandos centralizados, as diversas etapas, espacialmente segmentadas, da produção.

O uso de ambos os conceitos serve como resposta à questão formulada por Santos $(1985$, p. 61) de "como compreender o comportamento desse espaço indivisível diante do processo de acumulação, isto é, em função do trabalho comum das diversas instâncias da produção?" Os conceitos, como exposto anteriormente, conseguem apreender de maneira indissociável as particularidades de cada etapa da produção, captando o objeto da geografia como uno e total.

Numa tentativa de orientação metodológica e operacionalização do conceito de circuito espacial da produção, sugerimos como necessário para sua identificação, a análise de alguns temas principais: a atividade produtiva dominante, os agentes envolvidos e seus círculos de cooperação, a logística e o uso e organização do território.

No primeiro passo, como a análise dos circuitos espaciais produtivos parte do produto, é necessária a identificação da atividade produtiva dominante, analisando os seus principais aspectos técnicos e normativos.

$\mathrm{O}$ reconhecimento dos principais agentes envolvidos e as formas como estabelecem os círculos de cooperação é outro item fundamental. Assim como as etapas da produção estão geograficamente dispersas, os agentes que as animam também se encontram em localizações diferenciadas, possuindo maior ou menor poder de colocar a produção em movimento. Os diversos agentes, com objetivos e perspectivas próprios, se inter-relacionam dentro de círculos de cooperação cada vez mais intensos e extensos. Dentro dos circuitos espaciais produtivos, são estabelecidos diversos círculos de cooperação: entre as empresas; entre empresas e poderes públicos locais, regionais e nacionais; entre empresas, associações e instituições etc. É necessário, portanto, analisar as especificidades dos círculos de cooperação estabelecidos e as respectivas escalas de poder dos diferentes agentes.

A logística, compreendida como a expressão geográfica da circulação corporativa (CASTILLO, 2008), permite analisar as condições materiais e o ordenamento dos fluxos que perpassam os circuitos espaciais produtivos. No atual período da globalização, a idéia de logística passou a ser fundamental para o entendimento de como os diversos momentos do processo produtivo são articulados pelas grandes corporações, da escala local à mundial. A dimensão infra-estrutural da logística (redes técnicas e outros equipamentos) merece especial atenção, uma vez que, através delas, se estabelece a conexão entre as diversas instâncias separadas da produção. Em sua dimensão material, as redes podem ser classificadas em linhas, cada vez mais extensas, e pontos, considerados como "nós" das redes, cada vez mais seletivos e dispersos. As linhas podem ser subdivididas em materiais e imateriais; extravertidas (vinculadas ao mercado externo) e intravertidas (voltadas para a integração territorial interna). Os pontos devem ser observados quanto às suas densidades técnicas e normativas, das quais decorrem sua maior ou menor funcionalidade ao circuito espacial. Como a rede é uma realidade não apenas material, mas também social (SANTOS, 1996; DIAS, 2005), em alguns casos a regulação política que define a propriedade (pública, privada, concedida) e o acesso às redes deve ser levada em consideração na análise.

Por fim, ainda é preciso examinar atentamente a organização e o uso do território das diversas etapas do circuito espacial produtivo. A decisão a respeito da localização das atividades produtivas dominantes é fruto, sobretudo, no atual período, de decisões corporativas sobre os atributos materiais (naturais e técnicos) e normativos presentes em cada lugar. Cabe ao pesquisador entender o sentido dessa localização. A identificação da hierarquia entre os lugares também faz parte desse procedimento analítico, distinguindo os lugares que produzem massa e abrigam o comando técnico da produção dos lugares que produzem fluxos e detém o comando político da produção (SANTOS, 1996) e inúmeros casos intermediários. De maneira geral, o uso e a organização territorial referem-se à quantidade, à qualidade, à distribuição e ao arranjo espacial dos sistemas de objetos envolvidos na circularidade da produção, e a maneira como são usados, possibilitando verificar, a um só tempo, a organização interna dos subespaços, o uso seletivo dos sistemas técnicos e a forma como são estabe- 
lecidas as relações com outros subespaços. Cada lugar abriga, ao mesmo tempo, diferentes etapas de diversos circuitos espaciais produtivos, permitindo: 1) confrontar a configuração territorial pretérita com os novos arranjos espaciais produtivos; 2) avaliar o papel das densidades normativas, inclusive as solidariedades institucionais e as relações de conflito e cooperação entre as diversas escalas do poder público; 3) identificar a hierarquia entre os lugares e as diversas temporalidades coexistentes.

\section{CIRCUITO ESPACIAL E CADEIA PRODUTIVA: UMA DISTINÇÃO NECESSÁRIA}

Na qualidade de instância da sociedade, o espaço geográfico se iguala e se articula à economia, à política, ao direito e à cultura como conjuntos de fatores, funções e valores que perfazem domínios ou esferas de condicionamento da produção e da reprodução social, como já foi assinalado. Por força da divisão acadêmica do trabalho, algumas disciplinas acabam se encarregando de cada um desses domínios - daí a necessidade permanente de restituição dos estudos particulares ao todo ao qual pertencem, uma vez que "uma disciplina é uma parcela autônoma, mas não independente, do saber geral" (SANTOS, 1996).

A Economia, a Sociologia, a Ciência Política, o Direito e a Geografia enquadram-se nesses estudos particulares, constituindo-se, portanto, em conhecimentos complementares e, por isso mesmo, distintos. Como decorrência, e sem prejuízo das abordagens interdisciplinares, a formulação de teorias em cada disciplina científica pressupõe um sistema interno e particular de conceitos, suficientemente abertos para dialogar e se relacionar com as teorias provenientes de outros campos do conhecimento.

Com base nesses pressupostos, consideramos que os conceitos de cadeia produtiva e de circuito espacial produtivo pertencem a corpos teóricos e respondem a objetivos distintos, mas compartilham vários pressupostos e alguns procedimentos analíticos, tornando oportuno o estabelecimento de suas diferenças.

A idéia de cadeia produtiva (e suas derivações, tais como cadeia de valor e cadeia de suprimentos) vem sendo utilizada pelas Ciências
Sociais Aplicadas, destacadamente a Economia e a Administração, e pela Engenharia de Produção, com base nas proposições de estudiosos da economia corporativa e da logística, destacadamente Michael Porter $(1993 ; 1999)$. A partir da emergência do novo paradigma produtivo e do ideário da competitivida$d e$, nos anos 1970, seu uso torna-se mais difundido e mais pragmático. De metáfora à conceito, o uso do termo "cadeia produtiva" tem por objetivo permitir ou facilitar a visualização, de forma integral, das diversas etapas e agentes envolvidos na produção, distribuição, comercialização (atacado e varejo), serviços de apoio (assistência técnica, crédito etc.) e consumo de uma determinada mercadoria, de forma a: 1) permitir uma visão sistêmica, ao invés de fragmentada, das diversas etapas pelas quais passa um produto, antes de alcançar o consumidor final; 2) identificar "gargalos" que comprometam a integração dos diversos segmentos, garantindo ou promovendo a competitividade.

São incontáveis as formulações conceituais de cadeia produtiva, sobretudo quando ao termo se agregam as idéias de cadeia de valor (value chain), gerenciamento da cadeia de suprimentos (supply chain management) e logística. Para Dantas, Kersnetzky e Prochnik (2002, p. 37), "cadeia produtiva é um conjunto de etapas consecutivas pelas quais passam e vão sendo transformados e transferidos os diversos insumos", tanto na esfera das relações contratuais entre empresas (cadeia produtiva empresarial), quanto nas relações entre setores econômicos mediados pelo mercado (cadeia produtiva setorial).

Segundo Albagli e Brito (2003, p. 8), a cadeia produtiva inclui "matérias-primas, máquinas e equipamentos, produtos intermediários até os finais, sua distribuição e comercialização", implicando em crescente divisão do trabalho e especialização em etapas distintas do processo produtivo, em âmbito local, regional, nacional ou mundial. Também é essa a posição de Prochnik (2002) e Dantas, Kertsnetzky e Prochnik (2002, p. 36-37), para os quais,

As cadeias produtivas resultam da crescente divisão do trabalho e maior inderdependência entre os agentes economicos. Por um lado, as cadeias são criadas pelo processo de desin- 
tegração vertical e especialização técnica e social. Por outro lado, as pressões competitivas por maior integração e coordenação entre as atividades, ao longo das cadeias, amplia a articulação entre os agentes.

Frequentemente, as idéias de logística (moderna) e de cluster (ou de Arranjos Produtivos Locais) são associadas à noção de cadeia produtiva. Haguenauer e Prochnik (2000, p. 31), ao estabelecer os vínculos entre cluster e cadeias produtivas, destacam que, mais importantes do que a disponibilidade de mercados ou de matérias-primas, são os vínculos técnicos e econômicos "entre os setores e os impulsos que decisões em uma indústria ou expectativas sobre o comportamento futuro acarretam sobre as demais". Nessa mesma linha de raciocínio, Pires (2001, p. 80, apud SILVA, 2004, p. 179) afirma que

o maior benefício do estudo de uma cadeia produtiva é a possibilidade de ampliação da compreensão do contexto onde as empresas estão inseridas, fazendo com que as mesmas caminhem no sentido de ter uma visão sistêmica de sua competitividade. No momento em que os atores regionais começam a perceber as interrelações existentes entre os diferentes elos da cadeia produtiva, os seus "gargalos" começam a ficar mais claros, isto é, os pontos de estrangulamento da competitividade regional e das próprias empresas, onde esforços conjuntos podem produzir ganhos para todos os envolvidos.

Uma abordagem bastante difundida das cadeias produtivas a partir de arranjos empresariais é conhecida como filière. Trata-se da "sucessão de operações de transformação sobre bens e produtos, dissociáveis e separáveis, as quais são ligadas entre si por encadeamentos tecnológicos", através de "relações comerciais e financeiras, que regulam as trocas que ocorrem nos diferentes estágios de transformação dos produtos" (TALAMINI; PEDROZO, 2004, p. 3). Nessa aproximação, a análise se dá de jusante (mercado) a montante (produtos primários), visando medir a competitividade empresarial e setorial, considerando fatores internos e externos (mercados intermediários, diferenças regionais e culturais relacionadas ao ambiente e à força de trabalho entre outros) às empresas e aos aglomerados de empresas.

Dessa breve discussão, conclui-se que o conceito de cadeia produtiva vincula-se a uma crescente demanda por organização das atividades empresariais, frente ao atual paradigma produtivo, com o objetivo de elevar a competitividade de produtos e serviços, através da reestruturação de processos produtivos e da racionalização dos fluxos. Envolve a integração funcional entre diversas empresas ou setores de produção, armazenamento, distribuição e comercialização, serviços de apoio e estrutura normativa e regulatória. $\mathrm{O}$ foco encontra-se nas empresas ou nos aglomerados de empresas e nas relações estabelecidas entre elas, considerando os "ambientes" institucional (leis e regulações) e organizacional (centros de pesquisa, Universidades, órgãos públicos, certificadoras etc.) como externalidades favoráveis ou desfavoráveis ao desempenho empresarial ou setorial.

\section{A dimensão geográfica dos circuitos de produtos}

São muitas as semelhanças entre os conceitos de cadeia produtiva e de circuito espacial produtivo. Em ambas as abordagens, trata-se de apreender a unidade das diversas etapas do processo produtivo (produção propriamente dita, distribuição, troca e consumo), acompanhando todas as etapas de transformação e agregação de valor pelas quais passa um produto, da produção ou extração da matéria-prima até o consumo final, bem como os diversos serviços associados à distribuição, armazenamento, comercialização, crédito, pesquisa e desenvolvimento etc. O reconhecimento da importância da informação e de suas tecnologias como elementos de unificação entre as diversas etapas produtivas e a constatação da especialização produtiva ou do aprofundamento da divisão do trabalho, além de outros pressupostos característicos do atual período histórico, são compartilhados por um e outro.

Porém, os objetivos e o sistema de conceitos a que cada uma dessas noções pertence são distintos. Como adverte Silveira (2005, p. 217), ao tratar das diversas abordagens do "fenômeno agroindustrial" e sua operacionalização metodológica, diversos con- 
ceitos podem ser elaborados para tratar do mesmo fenômeno, mas expressam "distintas possibilidades analíticas e oferecem-se a diferentes objetivos de pesquisa". A idéia de cadeia produtiva surge no âmbito da administração de empresas e da busca por maior racionalidade econômica, visando ganhos de competitividade de agentes e de setores, pressupondo que esse objetivo traz benefícios para o conjunto da sociedade, mormente a local. Outrossim, faz parte de um sistema de conceitos e idéias que inclui a divisão técnica e social do trabalho, o desenvolvimento local (arranjos e sistemas produtivos locais e/ou clusters), competitividade sistêmica (do produto e da empresa), integração funcional entre outros. $\mathrm{Na}$ abordagem da cadeia produtiva, considera-se o espaço e a região como parte do "ambiente externo", como um fator que pode afetar, positiva ou negativamente, o processo produtivo.

A abordagem proposta pelo circuito espacial produtivo, por sua vez, desloca o foco da empresa para o espaço geográfico. O objetivo deixa de ser a identificação de gargalos que dificultem a plena integração funcional e prejudiquem a competitividade final dos produtos e passa a ser as implicações sócioespaciais da adaptação de lugares, regiões e territórios aos ditames da competitividade, bem como o papel ativo do espaço geográfico na lógica de localização das atividades econômicas, na atividade produtiva e na dinâmica dos fluxos.

Para melhor compreender os objetivos e as possibilidades analíticas do conceito de circuito espacial produtivo, é necessária uma pequena incursão no domínio da teoria geográfica. Partimos do pressuposto de que o espaço geográfico deve ser pensado como um conjunto de formas materiais (naturais e artificiais, articuladas ou não) que impõe resistências, oferece abrigo, expõe ao perigo, separa, unifica etc., somado a um conjunto de permissões e proibições que regula a maneira como cada porção pode ser apropriada, transformada e usada. No período histórico atual, o comportamento sistêmico das formas e das normas alcança todo o planeta, autorizando uma conceituação de espaço geográfico, tal como propõe Santos (1996, p.51):

O espaço é formado por um conjunto indissociável, solidário e também contraditório, de sistemas de objetos e sistemas de ações, não considerados isoladamente, mas como o quadro único no qual a história se dá.

Com isso, queremos dizer que o espaço geográfico é um híbrido (LATOUR, 1994; SANTOS, 1996) constituído pela combinação de coisas materiais (naturais e construídas social e historicamente) entre si e com as normas (sociais, políticas, jurídicas, econômicas, culturais) que regulam o uso, o acesso e a propriedade dessas coisas. De acordo com essa concepção, a competitividade ganha uma nova dimensão, que deriva da articulação, em algumas frações do espaço, entre formas materiais (acessibilidade, infra-estruturas produtivas, de circulação, comunicação, energia elétrica, abastecimento de água, sistemas de armazenamento, terminais multimodais e outras categorias de instalações e equipamentos, mais ou menos especializados) e normas (benefícios fiscais, outros incentivos a partir de recursos públicos locais, acordos entre instituições de pesquisa e empresas etc.) que garantem elevados níveis de produtividade e de fluidez. Trata-se da competitividade como atributo do espaço, particularmente da região.

A idéia de circuito espacial produtivo emerge dentro dessa concepção e seus objetivos são: 1) compreender o uso do território através da dinâmica dos fluxos, acentuada no atual período histórico; 2) identificar a situação dos lugares em relação à divisão territorial do trabalho na escala nacional, num dado momento (SANTOS, 1986, p. 130); 3) apreender o embate estabelecido entre uma lógica dos territórios e uma lógica das redes. Esse conceito encontra seu pleno sentido num campo semântico que envolve as idéias de divisão espacial do trabalho (MASSEY, 1995), divisão territorial do trabalho (SANTOS, 1996), especialização regional produtiva (SANTOS, 1994), círculos de cooperação no espaço (SANTOS, 1994), competitividade regional (GIORDANO, 1999), formação sócio-espacial (SANTOS, 1977), formação territorial (MORAES, 2000), desenvolvimento geograficamente desigual (SOJA, 1989; SMITH, 1988), entre outras. Em todos esses casos, trata-se de trazer à tona o espaço geográfico como instância da sociedade, no âmbito de uma teoria social crítica. 


\section{CIRCUITOS ESPACIAIS DE PRODUTOS AGRÍCOLAS EM ÁREAS DE FRONTEIRA NO TERRITÓRIO BRASILEIRO}

São inúmeras as formulações conceituais elaboradas para apreender a dinâmica da produção agrícola e agroindustrial e a articulação dos agentes envolvidos nessas atividades. Agribusiness (DAVIS; GOLDBERG, 1957), sistema de commodities (ZYLBERSZTAJN, 2000), filière / cadeia agroalimentar (MALASSIS, 1973), complexo agroindustrial (MÜLLER, 1989; SILVA, 1998), organização em rede (MAZZALI, 2000), redes de poder (PAULLILO, 2000) são alguns dos conceitos mais empregados.

As concepções acima expressam, de diversas formas, as idéias já expostas de cadeia produtiva, de relações sistêmicas, de articulação de etapas produtivas decorrentes da intensificação da agroindustrialização e das trocas internacionais de produtos agrícolas e derivados, a partir da segunda metade do século XX. Dessa miríade conceitual, cumpre destacar a noção de rede agroindustrial (SILVEIRA, 2005), por ser aquela que expressa uma abordagem autenticamente geográfica, uma vez que considera os lugares e os territórios que abrigam as atividades agroindustriais como variáveis ativas dos processos produtivos, da circulação e do ambiente regulatório. Segundo Silveira (2005, p. 230), "devemos ter presente que o território, através de suas contingências, características e atributos ambientais, socioculturais, econômicos e técnicos, oferece distintas possibilidades e estabelece determinadas condições, quanto ao seu uso, pelos agentes que participam do complexo agroindustrial". Com a ajuda dessa abordagem, podemos reconhecer alguns elementos intrínsecos aos circuitos espaciais de produtos agrícolas.

Destarte, para tratar desses últimos, é preciso enfatizar que a expansão do agronegócio e a lógica das commodities agrícolas são manifestações da unicidade técnica planetária (SANTOS, 1994), da mundialização das normas e da internacionalização dos mercados, em consonância com o "pensamento único" da globalização (SANTOS, 2000). No Brasil, o agronegócio tem atingido sucessivos superávits na balança comercial, alcançando em 2008 a cifra histórica de US\$ 60 bilhões. O PIB do agronegócio corresponde a cerca de um terço do PIB brasileiro, com exportações que atingiram US\$ 71,9 bilhões em 2008, correspondendo a $33,6 \%$ do total exportado pelo Brasil. Os principais países de destino são China (11\% dos embarques), Países Baixos (9\%) e Estados Unidos (8,7\%). A produção de soja e derivados proveniente, sobretudo, das áreas de fronteira agrícola moderna, principalmente em áreas do Cerrado, é a principal responsável pelos números expressivos do agronegócio brasileiro, com $25 \%$ do valor total das exportações.

Sob a superfície desses números, revela-se um fenômeno singular: o aumento concomitante da área e da arena de produção, resultante da combinação entre uma acelerada modernização agrícola a partir do pós-guerra (SILVA, 1998) e a presença de fundos territoriais (MORAES, 2002), ampliando os circuitos espaciais agrícolas e agroindustriais. A arena de produção corresponde ao espaço de produção stricto sensu, ou seja, aos hectares destinados ao cultivo dos grãos. Neste caso, o território brasileiro é um dos últimos a possuir áreas disponíveis à expansão da produção agrícola. Já a área de produção, compreendida como todo o espaço utilizado para a produção de um determinado produto, desde a produção em si até o consumo final, tornou-se mundial. Essa internacionalização dos circuitos espaciais produtivos mudou a qualidade da inserção do Brasil nos mercados internacionais. Os grãos produzidos na região dos cerrados brasileiros percorrem milhares de quilômetros (por rodovias, ferrovias e hidrovias) até os portos exportadores e daí são transportados por navios até os mercados consumidores, sobretudo da China e da Europa. Essa internacionalização dos capitais agroindustriais não encontra, nas áreas de fronteira agrícola no Brasil, fortes heranças espaciais, decorrendo daí uma menor resistência das populações locais ao uso corporativo do campo e das cidades. A articulação das relações de produção pré-existentes com grandes fazendeiros, vindos principalmente da região Sul, e tradings agrícolas, tem provocado enorme concentração fundiária, degradação ambiental e expulsão de pequenos produtores familiares.

A ampliação dos circuitos espaciais de produtos agrícolas exige uma logística eficiente, envolvendo um número maior de regiões e agentes, e torna necessária a proliferação de normas que facilitem e 
racionalizem a circulação das mercadorias. No caso das commodities agrícolas brasileiras, observamos a criação de um número acentuado de planos, programas e leis, nos âmbitos dos governos federal e estaduais, que procuram racionalizar a fluidez dos grãos.

Dentre as principais regiões produtoras, destacam-se as áreas de Cerrado na região CentroOeste e no sudeste de Rondônia, oeste da Bahia, sul do Maranhão e Piauí, Triângulo Mineiro e oeste de Minas, fazendo emergir questões que envolvem o conjunto do território brasileiro, como a grande distância em relação aos principais portos exportadores e a pronunciada especialização regional em produtos vulneráveis às oscilações dos mercados internacionais. Nestas áreas, difunde-se uma série de investimentos públicos e privados em sistemas técnicos vinculados à produção, como novos sistemas de transporte, comunicação, armazenamento e processamento, centros de pesquisa, revendas de maquinário agrícola e agrotóxicos, escritórios comerciais e agências bancárias. Junto a esses novos sistemas técnicos agrícolas, difunde-se também um aparato normativo que visa conferir maior eficiência e fluidez à produção, como a Lei de Modernização dos Portos, a Lei Kandir (desonera a exportação de produtos primários), concessão de ferrovias e hidrovias à iniciativa privada, novas normas vinculadas ao crédito (entrada de novos agentes no financiamento da produção) e ao seguro agrícola (zoneamento de risco climático), parcerias entre agentes públicos e privados para a construção e pavimentação de rodovias, como o Programa Estradeiro do Governo do Mato Grosso.

A implantação e o uso desses novos sistemas técnicos e normativos resultam do estabelecimento de círculos de cooperação entre os diferentes agentes que participam dos circuitos espaciais produtivos agrícolas. Os círculos de cooperação transcendem o território brasileiro, envolvendo uma diversidade de Estados, empresas e agentes financeiros internacionais. As relações estabelecidas entre os diversos agentes vão desde a pavimentação de rodovias, transporte e armazenamento dos grãos, até o financiamento agrícola e aplicações financeiras em Bolsas de Valores nos Estados Unidos e Europa. A maneira como cada agente se insere no circuito espacial produtivo e a forma como constitui suas relações revelam uma hierarquia. Aqueles que conseguem controlar a circulação, colocando a produção em movimento, são os que detêm o poder. Poderíamos acrescentar que, no circuito espacial produtivo da soja, em áreas consolidadas da fronteira agrícola moderna, as regiões mais competitivas (incluindo o campo e a cidade) são reféns dos mercados internacionais e vulneráveis à lógica global das commodities.

\section{CONSIDERAÇÕES FINAIS}

As novas bases técnicas e normativas, próprias do período da globalização, permitiram a planetarização de variados circuitos espaciais produtivos e de seus correspondentes círculos de cooperação. A difusão das redes de transportes e comunicações, acompanhada de normas (jurídicas, produtivas, financeiras), criadas para facilitar as trocas entre diversas regiões e países, difundiu uma mesma racionalidade de uso do território.

Frações dos territórios nacionais vem se organizando, mediante ações dos poderes públicos e influência de grandes corporações, para abrigar etapas do processo produtivo que extrapolam as fronteiras das formações sócio-espaciais (SANTOS, 1977). Lugares e regiões se especializam em determinadas etapas de diferentes circuitos espaciais produtivos, ampliando a divisão territorial do trabalho e tornando-se submissos a ordens e lógicas externas.

A racionalidade dominante da competitividade e do crescimento econômico coloca os diversos lugares em competição, numa verdadeira guerra para atrair investimentos e se inserir nos circuitos espaciais produtivos mundializados. Constituem-se, assim, regiões competitivas, áreas funcionais à produção hegemônica, obedientes a parâmetros internacionais de qualidade e custos.

No Brasil, e possivelmente também em outros países, essa disputa por mais investimentos tem contribuído para fragmentar o território, ampliando as históricas desigualdades sócio-espaciais em diversas escalas, uma vez que a crescente especialização produtiva, desprovida do controle político da produção, torna vulnerável o lugar e a região. A lógica de funcionamento da produção e dos fluxos que perpassam suas diferentes etapas extrapola a região, atribuindo a esse 
recorte do espaço geográfico novos contornos, novos propósitos e novas solidariedades. O que já foi um dia a expressão da relação entre uma fração do espaço e uma fração da sociedade, na longa duração, tão bem apreendida pelo geógrafos clássicos, não passa hoje de um legado histórico, uma variável subordinada a uma nova lógica de formação regional, pautada pelo ideário da competitividade e pelos parâmetros dos mercados internacionais e desprovida de autonomia produtiva. Nesses termos, como é possível falar em "desenvolvimento" local sustentado e sustentável, como preconizam geógrafos, economistas e autoridades públicas?

Como encaminhar teoricamente as ações, diante da relação diretamente proporcional entre a mundialização dos circuitos espaciais produtivos e o aumento da vulnerabilidade dos lugares, das regiões e dos territórios?

Sem a pretensão de dar resposta definitiva a essa questão, consideramos que, em primeiro lugar, é preciso resgatar a idéia de território como o compartimento político-institucional do espaço, delimitado por fronteiras dentro das quais tem vigência um sub-sistema jurídico amparado na soberania territorial nacional (e em suas subdivisões internas), supondo, portanto, o papel protagonista do Estado (MORAES, 2002) e a perseverante importância da sociedade nacional, ainda que seja recorrente, nos dias de hoje, anunciar a debilidade de um e o desaparecimento da outra. Uma outra política que oriente a inserção dos espaços infra-nacionais na globalização (SANTOS, 2000), através da ampliação dos circuitos espaciais produtivos, somente é possível dentro desses parâmetros, se o objetivo é escapar da integração externa subordinada (RICÚPERO, 2000) e da desintegração interna competitiva (ARAÚJO, 2000).

Dentro da atual estrutura regulatória, expressa num jogo de forças que inclui as grandes empresas e diversas modalidades de organização da sociedade civil, costuma-se admitir que a soberania territorial seja compartilhada com agentes orientados por formas de regulação não-estatal (HIRST; THOMPSON, 1998). Ainda assim, o Estado é o único agente que tem (ou deve ter) responsabilidade para com a totalidade do território e da população.
A divulgada idéia de responsabilidade social e ambiental da empresa é uma falácia ou, no máximo, uma jogada de marketing, e as chamadas "organizações não-governamentais", quando cumprem seus objetivos explícitos, somente podem dar conta de uma pequena parcela da sociedade e do território e não têm legitimidade política para fazer mais do que isso.

À forma histórica atual da divisão territorial do trabalho corresponde uma forma, também historicamente determinada, de circulação. Entendemos que o conceito de circuito espacial produtivo, tal como discutido nesse texto, apreende adequadamente o papel da circulação no período histórico atual.

Esse conceito nos obriga a reconhecer a existência de uma lógica dos territórios e uma lógica das redes, de cujo embate permanente criam-se e recriamse distintos modos de produzir e de circular, que coexistem de forma articulada e conflituosa, disputando espaços e recursos. A logística, emergente a partir da ampliação dos circuitos produtivos, somente ganhou importância e se constituiu como setor de atividade econômica justamente porque os territórios, entendidos como totalidade, são, do ponto de vista dos capitais mais modernos, irracionais, uma vez que resultam da interação entre muitos agentes e do confronto entre diversos interesses.

Essa "irracionalidade" se exprime, por exemplo, nas passagens em nível, invasões de domínios ferroviários, rodovias precárias, caminhões circulando com sobrepeso, frete rodoviário mantido artificialmente baixo, hidrovias sem sinalização, portos assoreados e de baixo calado, mas também nos produtores agrícolas recalcitrantes, nos movimentos sociais de luta pela reforma agrária e no amplo espectro do circuito inferior da economia urbana (SANTOS; SILVEIRA, 2001), freqüentemente criminalizado e considerado nocivo aos grandes negócios.

A noção tradicional de região, a velha geografia dos transportes e os modelos de crescimento econômico contidos nos manuais de administração pública ou corporativa não dão conta de explicar as situações atuais, exigentes de uma renovação conceitual capaz de superar tanto os discursos coniventes quanto as críticas desprovidas de análise. 


\section{REFERÊNCIAS}

ALBAGLI, S.; BRITTO, J. (Org.). Glossário de arranjos produtivos locais. Projeto Políticas de Promoção de Arranjos Produtivos Locais de MPMEs. Rio de Janeiro: UFRJ/RedeSist, 2003. Disponível em: $<$ www.ie.ufrj.br/redesist $>$. Acesso em: 20 jul. 2008.

ANTAS JR., R. M. Território e regulação: espaço geográfico, fonte material e não-formal do direito. São Paulo: Associação Editorial Humanitas: Fapesp, 2005.

ARAÚJO, T. B. Dinâmica regional brasileira nos anos noventa: rumo à desintegração competitiva. In: CASTRO, I. E. et al. (Org.). Redescobrindo o Brasil: 500 anos depois. Rio de Janeiro: Bertrand Brasil, 2000. p. 73-92.

ARROYO, M. Território nacional e mercado externo: uma leitura do Brasil na virada do século XX. 2001. 250f. Tese (Doutorado em Geografia Humana). FFLCH, USP. São Paulo, 2001.

. A economia invisível dos pequenos. Le Monde Diplomatique Brasil. São Paulo, p. 31-31, out. 2008.

BARRIOS, S. Dinámica Social y Espacio. CENDES. Universidad de Venezuela. Caracas, 1976.

CASTILLO, R. Sustentabilidade, globalização e desenvolvimento. In: OLIVEIRA, M. P. de et al. (Org.). O Brasil, a América Latina e o mundo: espacialidades contemporâneas. Rio de Janeiro: Anpege / Clacso / Faperj / Lamparina, 2008. p. 401-410.

DANTAS, A.; KERTSNETZKY, J.; PROCHNIK, V. Empresa, indústria e mercados. In: KUPFER, D.; HASENCLEVER, L. (Org.). Economia industrial: fundamentos teóricos e práticas no Brasil. Rio de Janeiro: Campus, p. 23-41, 2002.

DAVIS, J. H.; GOLDBERG, R. A. A Concept of Agribusiness. Boston: Havard University Press, 1957.

GIORDANO, S. Competitividade regional e globalização. 1999. 225f. Tese (Doutorado em Geografia) - FFLCH/USP, São Paulo, 1999.
HAGUENAUER, L.; PROCHNIK, V. Identificação de cadeias produtivas e oportunidades de investimento no Nordeste. Fortaleza: Banco do Nordeste, 2000.

HIRST, P.; THOMPSON, G. Globalização em questão: a economia internacional e as possibilidades de governabilidade. Petrópolis: Vozes, 1998.

LATOUR, B. Jamais fomos modernos: ensaio de antropologia simétrica. Rio de Janeiro: Editora 34, 1994.

MALASSIS, L. Agriculture et processus de développement: essai d'orientation pédagogique. Paris: Unesco, 1973.

MARX, K. Contribuição à Crítica da Economia Política. São Paulo: Expressão Popular, 2008.

MASSEY, D. B. Spatial divisions of labour: social structures and the geography of production. 2 ed. New York: Routledge, 1995.

MAZZALI, L. O processo recente de reorganização agroindustrial: do complexo à organização "em rede". São Paulo: Ed. Unesp, 2000.

MORAES, A. C. R. de. Los circuitos espaciales de la producción y los círculos de cooperación em el espacio. In: YANES, L. et al. (Org.), Aportes para el estúdio del espacio socioeconômico, tomo III, El Colóquio. Buenos Aires: [s.n.], 1985.

- Bases da formação territorial do Brasil: o território colonial brasileiro no "longo" século XVI. São Paulo: Hucitec, 2000.

Território e história no Brasil. São Paulo: Hucitec, 2002.

MÜLLER, G. Cem anos de República: notas sobre as transformações estruturais no campo. Estudos Avançados. São Paulo, vol.3, n.7, dez. 1989, p.109-136.

PAULLILO, L. F. Redes de poder e territórios produtivos. São Carlos: Ed. UFSCar, 2000. 
PORTER, M. A vantagem competitiva das nações. Rio de Janeiro: Campus, 1993.

. Competição: estratégias competitivas essenciais. 4. ed. Rio de Janeiro: Campus, 1999.

PROCHNIK, V. Firma, indústria e mercados. In: HASENCLEVER, L.; KUPFER, D. (Org.). Organização industrial. Rio de Janeiro: Campus, 2002.

RICÚPERO, R. Integração externa, sinônimo de desintegração interna? Estudos Avançados 14 (40), p.13-22, 2000.

SANTOS, M. Sociedade e espaço: a formação social como teoria e como método. Boletim Paulista de Geografia. São Paulo, n. 54, AGB, 1977, p.35-59.

Por uma geografia nova. Da crítica da geografia a uma geografia crítica. São Paulo: Edusp, 1978.

Espaço e método. São Paulo: Nobel. 1985.

Circuitos espaciais da produção: um comentário. In: SOUZA, M. A. A.; SANTOS, M. (Org.). A construção do espaço. São Paulo: Nobel, 1986. p. 121-134.

. Metamorfoses do espaço habitado. São Paulo: Hucitec, 1988.

Técnica, espaço, tempo: globalização e meio técnico-científico informacional. São Paulo: Hucitec, 1994.

- A natureza do espaço: técnica e tempo, razão e emoção. São Paulo: Hucitec, 1996.

. A totalidade do diabo: como as formas geográficas difundem o capital e mudam estruturas sociais. Ciência Geográfica. AGB - Seção Bauru, Edição Especial, 1997 [1977. p. 31-43].

. Por uma outra globalização: Do pensamento único à consciência universal. Rio de Janeiro e São Paulo: Record, 2000.
O espaço dividido: os dois circuitos da economia urbana nos países subdesenvolvidos. São Paulo: Edusp, 2004 [1979].

SANTOS, M.; SILVEIRA, M. L. O Brasil: território e sociedade no início do século XXI. São Paulo: Record, 2001.

SILVA, J. A. S. Turismo, crescimento e desenvolvimento: uma análise urbano-regional baseada em cluster. 2004. 480p. Tese (Doutorado em Relações Públicas, Propaganda e Turismo) - Escola de Comunicações e Artes / USP, 2004.

SILVA, J. G. da. A nova dinâmica da agricultura brasileira. 2 ed. Campinas, SP: Unicamp. IE, 1998.

SILVEIRA, R. L. L. da. Complexo agroindustrial, rede e território. In: DIAS, L. et al. (Org.), Redes, sociedades e territórios. Santa Cruz do Sul: Edunisc, 2005. p. 215-254.

SMITH, N. Desenvolvimento desigual: natureza, capital e a produção do espaço. Rio de Janeiro: Bertrand Brasil, 1988.

SOJA, E. Geografias pós-modernas: a reafirmação do espaço na teoria social crítica. Rio de Janeiro: Jorge Zahar, 1989.

TALAMINI, E.; PEDROZO, E. A. Matriz do tipo insumo-produto (MIP) de uma propriedade rural derivada do estudo de filière. Teor. e Evid. Econ. Passo Fundo, v. 12, n. 22, p. 77-103, 2004.

ZYLBERSZTAJN, D. Conceitos gerais, evolução e apresentação do sistema agroindustrial. In: ZYLBERSZTAJN, D.; NEVES, M. F. (Org.). Economia e gestão de negócios agroalimentares. São Paulo: Pioneira, 2000. 